\title{
Biopsy and sex determination by PCR of IVF bovine embryos
}

\author{
Z Macháty, A Páldi, T Csáki, Z Varga, I Kiss, Z Bárándi and G Vajta \\ Institute for Animal Sciences, Agricultural Biotechnology Center, Gödöllö, POB 170, H-2101, Hungary
}

Correspondence should be addressed to Z Macháty who is now at Department of Animal Sciences, Purdue University, West Lafayette, IN 47907, USA; Email: zmachaty@purdue.edu

The authors and journal apologize for an error in the above paper, which appeared in Journal of Reproduction and Fertility volume 98 part 2, pages 467-470. The size of the $Y$ chromosome-specific amplification product is 173 base pairs, not 301 base pairs as published. 